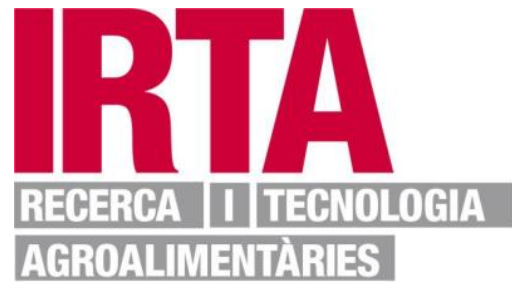

This is the peer reviewed version of the following article: Colom-Cadena, Andreu, Ignasi Marco, Xavier Fernández Aguilar, Roser Velarde, Johan Espunyes, Rosa Rosell, Santiago Lavín, and Oscar Cabezón. 2019. "Experimental Infection With High- And Low-Virulence Strains Of Border Disease Virus (BDV) In Pyrenean Chamois ( Rupicapra P. Pyrenaica ) Sheds Light On The Epidemiological Diversity Of The Disease". Transboundary And Emerging Diseases. Wiley. doi:10.1111/tbed.13195, which has been published in final form at https://doi.org/10.1111/tbed.13195. This article may be used for non-commercial purposes in accordance with Wiley Terms and Conditions for Use of Self-Archived Versions http://www.wileyauthors.com/self-archiving.

Document downloaded from: 
3

4

Article type : Original Article

6

8 Experimental infection with high- and low-virulence strains of border disease virus

(BDV) in Pyrenean chamois (Rupicapra p. pyrenaica) sheds light on the epidemiological

\section{diversity of the disease.}

COLOM-CAdena, Andreu ${ }^{1,2 *}$; MARCO, IGnasi ${ }^{1}$; Fernández Aguilar, Xavier ${ }^{1,3}$; Velarde,

RoseR $^{1}$; EsPUnYeS, JOHAN ${ }^{1,2}$; Rosell, Rosa ${ }^{4,5}$; LAvín, SANTIAGO ${ }^{1}$; CABEZÓN, OSCAR ${ }^{2,1}$

${ }^{1}$ Wildlife Ecology \& Health group (WE\&H), Servei d' Ecopatologia de Fauna Salvatge (SEFaS), Departament de Medicina i Cirurgia Animals, Universitat Autònoma de Barcelona (UAB), 08193, Bellaterra, Spain

${ }^{2}$ UAB, Centre de Recerca en Sanitat Animal (CReSA, IRTA-UAB), Campus de la

Universitat Autònoma de Barcelona, 08193 Bellaterra, Spain

${ }^{3}$ Department of Ecosystem and Public Health, Faculty of Veterinary Medicine, University of

Calgary, 3280 Hospital Dr. NW, Calgary, Alberta T2N 4Z6, Canada

${ }^{4}$ IRTA, Centre de Recerca en Sanitat Animal (CReSA, IRTA-UAB), Campus de la

Universitat Autònoma de Barcelona, 08193 Bellaterra, Spain

This is the author manuscript accepted for publication and has undergone full peer review but has not been through the copyediting, typesetting, pagination and proofreading process, which may lead to differences between this version and the Version of Record. Please cite this article as doi: 10.1111/TBED.13195

This article is protected by copyright. All rights reserved 
275 Departament d'Agricultura, Ramaderia, Pesca i Alimentació, Generalitat de Catalunya, 08007 Barcelona, Spain

*Email address: andreuccadena@gmail.com

Keywords: Border disease virus; Chamois; Experimental infection; Pestivirus; Rupicapra p. pyrenaica; Virulence.

Running title: High- and low-virulence strains of BDV in chamois

Summary

Since 2001, Pyrenean chamois (Rupicapra pyrenaica pyrenaica) populations have been affected by border disease virus (BDV) causing mortalities of more than $80 \%$ in some areas. Field studies carried out in France, Andorra and Spain have shown different epidemiological scenarios in chamois populations. The present study was designed to confirm the presence of BDV strains of a high and low virulence in free-ranging chamois populations from Pyrenees and to understand the implications of these findings to the diverse epidemiological scenarios.

An experimental infection of Pyrenean chamois with a high-virulence (Cadí-6) and lowvirulence (Freser-5) BDV strains was performed. Pregnant and non-pregnant animals with and without antibodies against BDV were included in each group. Cadí-6 BDV strain was confirmed to be of high virulence for seronegative adults and their foetuses. The antibody negative chamois infected with Freser-5 BDV strain did not show symptoms, presented less viral distribution and RNA load in tissues than Cadí-6 group, and cleared the virus from the serum. However, foetuses died before the end of the experiment and RNA virus was detected in sera and tissues although with lower RNA load than the Cadí-6 group. Chamois from both groups presented lesions in brain but the ones infected with the low-virulence Freser-5 BDV strain were mild and most likely transient. In both groups, seropositive pregnant females and all but one of their foetuses did not present viraemia or viral RNA in tissues.

The existence of a low-virulence strain has been confirmed experimentally and related to chamois population infection dynamics in the area where it was isolated. Such strain may persist in the chamois population through PI animals and may induce cross-protection in 
chamois against high-virulence strains. This study demonstrates that viral strain diversity is a significant factor in the heterogeneity of epidemiological scenarios in Pyrenean chamois populations.

\section{Introduction}

Border disease virus (BDV) is one of the four traditionally recognized species of the genus Pestivirus (Fam. Flaviviridae). Bovine viral diarrhea virus type 1 (BVDV-1), BVDV-2 and classical swine fever virus (CSFV) are the most studied due to their economic impact on livestock industries (Tautz et al., 2015). BDV is also of importance as it is associated to economic losses mainly in sheep flocks and interfering BVDV eradication programs in cattle (Nettleton et al., 1998; Kaiser et al., 2017). Moreover, BDV is the only member of the Pestivirus genus that has caused epizootic mortalities in a wild ruminant species (Marco et al., 2007).

Since 2001, Pyrenean chamois (Rupicapra pyrenaica pyrenaica) populations have been affected by BDV strains classified into the BDV-4 genogroup (Arnal et al., 2004), causing mortalities of more than $80 \%$ in some areas (Marco et al. 2009). Cabezón et al. (2011) performed an experimental infection in chamois demonstrating that a BDV-4 strain isolated from a diseased chamois causes long-lasting viraemia with pathological changes mainly characterized by non-suppurative meningoencephalitis. Martin et al. (2013) infected three pregnant Pyrenean chamois with the same BDV strain. All of the animals died before parturition, and foetal death, viral presence in foetuses and adult tissues with viraemia for at least 51 days were found.

In both of the abovementioned experimental infections, viral shedding was confirmed through nasal, rectal, oral and vaginal routes. Viral excretion was present from day 2 postinoculation (p.i.) (Cabezón et al., 2011) and from day 12 p.i. (Martin et al., 2013) onwards, highlighting the importance of horizontally infected chamois in this virus spread. In domestic ruminants, a key role in pestivirus maintenance at a population level is played by persistently infected (PI) animals. Although this epidemiological figure has not been clearly demonstrated in the Pyrenean chamois, an experimental infection of one pregnant chamois inoculated at 
day 90-100 of gestation showed an animal PCR pestivirus positive at birth and at the time of death 84 days later (Vautrain and Gibert, 2008).

Field studies carried out in France, Andorra and Spain have shown different epidemiological scenarios in chamois populations (Pioz et al., 2007; Martin et al., 2011; Marco et al., 2015). Pestivirus infections in chamois populations from the Pyrenees mainly cause mortality outbreaks with different impacts at the population level. After these episodes, at least two scenarios have been described: constant BDV circulation with negative impacts on population dynamics in some areas, or a lack of virus circulation and rapid recovery of the chamois population in others (Fernández-Sirera et al., 2012). Strikingly, pestivirus circulation has been detected in an area of the eastern Pyrenees (Freser-Setcases National Hunting Reserve) since 1996 without a significant impact on the chamois population (Marco et al., 2011). To date, no mass mortality, and only one clinical case has been found in this area where more than a half of the chamois population have neutralizing antibodies against pestivirus (Marco et al., 2015). Different hypotheses may explain the persistence of the pestivirus in this population, related to BDV strain variability, genetic diversity of chamois and/or environmental factors. In fact, all the 5' UTR sequences of BDV strains that have been isolated in the last fifteen years from Pyrenean chamois have clustered into the BDV-4 genogroup with low phylogenetic divergence, but geographical patterns of distribution have been proposed (Luzzago et al., 2016).

To shed light on the epidemiological diversity of pestivirus infections and to contribute to the knowledge of pathological implications of different strains from the same viral genogroup, we challenged experimentally Pyrenean chamois with both previously reported highvirulence and a presumptive low-virulence BDV strains. The main objectives of the study were: 1) To describe clinical, virological and pathological differences between infection with different strains; 2) To assess the impact of these strains on pregnant chamois and their foetuses; and 3) To evaluate the mechanisms of transmission and cross-protection to understand their implications on pestivirus epidemiology. 


\section{Animals: Capture and management}

119 Fifteen free-ranging Pyrenean chamois (11 females and 4 males between 3 and 16 years old) were captured by drive net (López-Olvera et al., 2009) in Freser-Setcases National Hunting Reserve (FS-NHR; northeastern Iberian Peninsula, 42²2’N, $\left.2^{\circ} 09^{\prime} \mathrm{E}\right)$. This reserve covers 20,200 hectares of alpine ecosystem in the Pyrenees mountains, where about 300 Pyrenean chamois are legally hunted per year. The captured animals were named $R p$ and consecutively numbered (ie. Rp 1 to $\mathrm{Rp} \mathrm{15).} \mathrm{Acepromazine} \mathrm{maleate}(0.1 \mathrm{mg} / \mathrm{kg}$; Calmivet $5 \mathrm{mg} / \mathrm{ml}$; Vétoquinol S.A., Lure Cedex, France) was administered to all chamois to reduce stress after capture (López-Olvera et al., 2007). In order to mitigate the adverse effects of stress in captivity, $1 \mathrm{mg} / \mathrm{Kg}$ Zuclopenthixol acetate (Clopixol Acuphase $50 \mathrm{mg} / \mathrm{ml}$; Lundbeck Limited, Valby, Denmark) was intramuscularly administered every three days. In addition, all the chamois were treated with a single intramuscular dose of $2.5 \mathrm{mg} / \mathrm{Kg}$ tulathromycin (Draxxin; Pfizer Animal Health, New York, USA), a single oral dose of $2.5 \mathrm{mg} / \mathrm{Kg}$ toltrazuril (Baycox 5\%; Bayer Animal Health Leverkusen, Germany) and a single subcutaneous dose of 0.2 $\mathrm{mg} / \mathrm{Kg}$ ivermectine (Ivomec 1\%; Merial Laboratorios S.A., Lyon, France), to prevent opportunistic bacterial and parasitic infections.

Before the challenge, all animals were tested for BDV and BVDV presence in sera by means of RT-PCR. Antibodies against BDV were assayed by a Virus Neutralization Test (VNT) to establish their immunological status for the challenge groups, as described below. Four out of fifteen animals ( $\operatorname{Rp~6,~7,~} 14$ and 15) showed antibodies and were included in the study as seropositive inoculated animals. Pregnancy of the females was confirmed by trans-rectal echography. The image test showed that 8 out of 11 females were pregnant. Although the time of gestation could not be determined accurately, it was estimated to be between 70 and 100 days based on the natural history of Pyrenean chamois and the capture date.

Inoculum

Two non-cytopathogenic BDV-4 strains where used as inoculum. The first virus, BDV Cadí6 (5'-UTR region; GenBank accession number AM905923), was isolated from a diseased chamois found in the Pyrenees (Cadí NHR) during an outbreak of disease and mortality in 2005. This virus was demonstrated as a highly virulent BDV-4 strain in a previous experimental infection (Cabezón et al., 2011). The second virus, BDV Freser-5 (5'-UTR region; GenBank accession number LT966297), was isolated from the spleen of an 
apparently viable foetus belonging to a healthy hunted female chamois from FS-NHR in 2014. As it was isolated from a healthy antibody-positive chamois from an area where no outbreaks had been recorded, we hypothesized that this could be a low-virulence BDV strain. Both BDV-4 strains were cultured in single and double passages in the SFT-R cell line (provided by the Friedrich-Loeffler Institute, Island of Riems, Germany). The virus titre of the inoculum was determined by end-point titration in the SFT-R cell line, obtaining a measurement of $10^{6} \mathrm{TCID}_{50} / \mathrm{ml}$ of virus.

\section{Study design}

The fifteen animals were divided into two groups - group A (GA) and group B (GB) - and placed in two isolated boxes in a level-3 biosafety area of the Centre de Recerca en Sanitat Animal (CReSA-IRTA, Universitat Autònoma de Barcelona, Spain) facilities for 26 days (Table-1). Within each group there were antibody negative animals (GA-1 and GB-1, five and six chamois, respectively) and antibody positive animals (GA-2 and GB-2, two chamois in each group). Two pregnant females were present in each group (Table 1). GA and GB were challenged with $10^{6} \mathrm{TCID}_{50} / \mathrm{ml}$ of Cadí-6 and Freser-5 strains, respectively. The whole virus dose was thawed immediately before inoculation and administered by a combination of nasal catheter $(0.5 \mathrm{ml}$ in each nostril) and orally $(1 \mathrm{ml})$. The duration of the challenge was 26 days. Chamois displaying any or combinations of the following signs during the challenge were euthanized: complete anorexia, recumbence with inability to rise, or signs of severe dehydration. Animal care activities and study procedures were conducted in accordance with the guidelines of Good Experimental Practices, with the approval of the Ethical and Animal Welfare Committee of the Universitat Autònoma of Barcelona.

\section{Sampling procedure}

The animals were observed daily to evaluate clinical signs. Blood samples were obtained by venipuncture of the jugular vein (days $0,2,4,8,15,19,26$ p.i.) and centrifuged at $1200 \mathrm{~g}$ for 15 minutes to obtain serum. Sera were stored at $-80^{\circ} \mathrm{C}$ until analysis. Blood from foetuses was obtained during necropsy. Nasal and rectal swabs were obtained on same days as blood samples. Swabs were mixed with $1 \mathrm{ml}$ of sterile PBS ( $\mathrm{pH} 7.2$ ) and stored at $-80^{\circ} \mathrm{C}$ until analysis. After necropsy, tissues for virological studies were weighed with a $0.1 \mathrm{~g}$ precision scale, homogenized in $0.9 \mathrm{ml}$ Eagle's Minimum Essential Medium (EMEM) and stored at $80^{\circ} \mathrm{C}$. Those samples were spleen, liver, bone marrow, kidney, Peyer patch, urine, lungs, brain and two lymph nodes (submandibular and retropharyngeal) for adult chamois, and thymus, spleen, brain, and placentome for foetuses. 


\section{Virus Neutralization Test}

Sera were tested for the presence of neutralizing antibodies against the homologous BDV strains CADI-6 (GA) and Freser-5 (GB) with the Virus Neutralization Test (VNT) (OIE, 2014). Briefly, serum samples were diluted 1:10 with sterile EMEM, heat-inactivated $\left(56^{\circ} \mathrm{C}\right.$ for $30 \mathrm{~min}$ ) and distributed in a twofold dilution series in 96-well plates (50 $\mu 1$ per well). After adding a volume of $50 \mu \mathrm{l}$ containing $100 \mathrm{TCID}_{50}$ of the homologous BDV, the plates were incubated at $37^{\circ} \mathrm{C}$ for an hour. Finally, $2.8 \times 10^{4}$ Madin-Darby bovine kidney (MDBK) cells $(100 \mu \mathrm{l})$ were added to each well. Replication was monitored using the immunoperoxidase monolayer assay (IPMA) (OIE, 2014) with a polyclonal pestivirus antibody produced in-house. Twelve dilutions from 1:10 to 1:20,480 were assessed by each serum sample (animal and sampling time). One well per dilution was used as a simplification of the standard instructions to get an approach of antibody dynamics in the two groups of infected animals. Titres were expressed as the reciprocal of the highest dilution that neutralized 100 TCID $_{50}$ in all cultures.

\section{Real-time Reverse Transcriptase-PCR}

Total viral RNA was extracted directly from $200 \mu 1$ of sera, swabs, urine and tissue samples using MagAttract 96 cador Pathogen Kit (Qiagen, Venlo, Netherlands) as per the manufacturer's instructions. A one-step reverse transcription-PCR kit was used for SYBR ${ }^{\circledR}$ Green-based real-time RT-PCR (Thermo-fisher Scientific, Waltham, Massachsetts, USA). Positive results were considered for threshold cycle values $(\mathrm{Ct})$ less than 40 . Differences in 3.3 Ct units were estimated to be a ten-fold increase in viral load (Nolan et al., 2006). Samples in which fluorescence was undetectable were considered negative.

Panpestivirus pimers 324 and 326 were used for the amplification reaction (Vilcek et al., 1994). . Analysis of the sequence of the 243 base pair 5'UTR fragment generated by RT-PCR was performed on positive samples from foetuses. Amplified DNA was purified and sequenced. The phylogenetic tree was made by the neighbour-joining method using an automatic root location. To test the reliability of the branches in the tree, a bootstrap analysis of 1,000 replicates was performed by creating a series of bootstrap samples.

\section{Pathological examination}

Necropsies and tissue sampling were performed according to standard protocols. The chamois were euthanized on day 19 p.i. (Rp 2), 22 p.i. (GA-2/GB-2) and 26 p.i. (GA-1/GB-1) 
with a lethal barbiturate injection. At necropsy, tissue samples (the same samples abovementioned for virological studies) collected for the histopathological examination were fixed in $10 \%$ neutral buffered formalin, embedded in paraffin, cut into $4 \mu \mathrm{m}$ sections and stained with haematoxylin and eosin according to standard procedures.

\section{Statistical analysis}

To assess statistically significant differences in mean $\mathrm{Ct}$ in sera, nasal and rectal swabs between GA and GB, or between GA-1/GB-1 and GA-2/GB-2 animals, a non-parametric unpaired Wilcoxon test (Mann-Whitney test) was used. Differences between Group A and B in median titres obtained by VNT were statistically assessed by the Mood's median test. The limit of significance was defined as $\mathrm{P} \leq 0.05$. All the analyses were carried out with the statistical software R version 3.4.0 (R Development Core Team, 2016).

\section{$\underline{\text { Results }}$}

\section{Clinical findings and pathological examination}

The main clinical observation in chamois from GA-1 was apathy, present in all but one animal from this subgroup. Three out of these five animals were found dead or were euthanized before the end of the experiment. Rp 2 was euthanized on 19 dpi because of severe apathy, prostration and dyspnea. Rp 4 and 5 were found dead at 15 dpi and 26 dpi, respectively. In GB-1, all animals remained active and apparently healthy with the exception of the two pregnant females ( $\operatorname{Rp} 8$ and 10) who presented mild apathy between 12 dpi and 17 dpi. Chamois from subgroups GA-2 and GB-2 remained active throughout the experimental period.

The three animals of GA-1 that died before the end of the experiment had lesions consistent with haemorrhagic diathesis. Petechial to ecchymotic haemorrhages were present in the subcutaneous tissue, in the serosa and mucosa along the gastrointestinal tract, lungs, epicardium and endocardium, mucosa of the urinary bladder and in the pregnant females in the placentomes. Despite neurological signs (ie. mainly apathy) were recorded in GA-1, lesions of different severity were seen in the brain not only in animals from GA-1, but also from GB-1. In GA-1, three out of five animals ( $R p 1, \operatorname{Rp} 2$ and $R p$ 5) had moderately severe non-suppurative meningoencephalitis with diffuse gliosis, glial nodules, perivascular oedema and inflammatory perivascular lymphohistiocytic infiltrates. Rp 3 presented similar lesions in 
a milder form, with only few scattered glial nodules and mild perivascular infiltrates and Rp 4 had only occasional area of microglial activation. Similarly to Rp 3, all animals from GB-1 presented mild non-suppurative meningoencephalitis with few small glial nodules and occasional lymphohistiocytic perivascular infiltrates. None of the seropositive animals from each group (GA-2 and GB-2) presented histopathological lesions in the brain at 26 dpi. Changes in lymph nodes and tonsils in GA-1 consisted mainly in moderate lymphoid depletion with loss of lymphoid follicles and decreased lymphoid density in interfollicular and paracortical areas except for Rp 3, where only small haemorrhages were seen. Lymphoid depletion or increase tingible body macrophages were not seen in GA-2, GB-1 and GB-2.

\section{Serology}

Neutralizing antibody titres were detected by VNT in chamois from GA-1 and GB-1 from 15 dpi until the end of the experiment (Fig. 1a; Supplementary table 1). In GB-1, antibody titres increased until 26 dpi reaching median titres of 1/1280 (range 1/640-1/2560). These titres were not statistically different from those of GA-1. Chamois from GA-2/GB-2 presented neutralizing antibodies before the experiment, as stated before, until the end of it.

\section{Viral RNA in sera and tissues}

A higher mean RNA load was found in sera samples of GA-1 from 4 dpi onwards, maintaining a difference between 4.3 and $8.9 \mathrm{Ct}$ - equivalent to a 10 to 100 -fold increase in viral load - from animals of GB-1 (Fig. 1a). Interestingly, Rp 3 from GA-1 only presented viral RNA at 8 dpi $(\mathrm{Ct}=26.63)$ and $26 \mathrm{dpi}(\mathrm{Ct}=34.37)$. At the end of the challenge, all the chamois from GB-1 have cleared the BDV as no viral RNA was detected in sera (Fig. 1b; Supplementary table 2) and tissues. Chamois from GA-2/GB-2 did not present viral RNA in sera during all the experiment.

BDV was found widely distributed in tissue samples in chamois without antibodies at the beginning of the experiment (GA-1) (Table 1). Interestingly, Rp 3 (GA-1) only presented viral RNA in the submandibular lymph node, tonsil and spleen, with a lower RNA load than the other GA-1 animals. In GB-1, viral RNA was found in lower quantities and less distributed than in GA-1. Differences ( $\geq 8 \mathrm{Ct}$ mean) were found in all tissues between GA-1 and GB-1 chamois, equivalent to more than a 100-fold increase in viral load. No GA-2 and GB-2 animals presented BDV RNA in tissues. 


\section{Viral shedding}

From 12 dpi onwards, all animals from GA-1 presented viral excretion in nasal fluids, with the exception of chamois Rp 3, which only presented viral RNA on 12 dpi with high $\mathrm{Ct}$ (32.684) (Fig. 2a). Differences from $3 \mathrm{Ct}$ to more than $10 \mathrm{Ct}$ were found in nasal swabs between GA-1 and GB-1 chamois. Regarding GA-2/GB-2 chamois, only animal Rp 7 presented low viral excretion $(\mathrm{Ct}=33.36)$ by the nasal route at $12 \mathrm{dpi}$.

RT-qPCR detected less viral shedding in rectal swabs than in nasal swabs and only in GA-1 (Fig. 2b). In the chamois Rp 3 rectal swabs, viral RNA was detected only at 12 dpi $(\mathrm{Ct}=33.79)$. Neither the GA-2, GB-1 nor GB-2 chamois presented the BDV genome in any of the rectal swab samples.

Regarding BDV presence in the urine collected at necropsy, four out of five chamois in GA-1 presented positive RT-qPCR results ( $\mathrm{Ct}$ mean=24.59, $\mathrm{sd}=3.6$ ). GA-2, GB-1, and GB-2 animals did not present viral RNA in urine samples (Table 1).

\section{Effects on pregnancy and foetus}

Clinical findings in pregnant females of GA-1 were characterized by apathy as with the other chamois in the same group. GB-1 pregnant females were the only animals in this group that presented mild and temporary apathy and Rp 10 aborted on 25 dpi. GA-2 and GB-2 pregnant females were apparently active and healthy throughout the experiment.

The post-mortem examination showed that the two foetuses from GA-1 died during the challenge (Fig. 3A-B). Severe placentitis was seen in both, with abundant clear haemorrhagic amniotic fluid, oedematous placenta and haemorrhagic caruncles. Foetuses had diffuse subcutaneous gelatinous fluid and fluid-filled cavities. The foetuses from GB-1 also died during the experiment. Rp 8 had necrotic placentomes and a mummified foetus of about 7-8 cm. Rp 10 aborted on 25 dpi. In this case, a malformation of the head was evident with marked shortening of the maxilla and the mandible (Fig. 3C-D). Subcutaneous gelatinous fluid in the foetus and necrotizing placentitis were also noted. In all cases of foetal death, the brain was soft and difficult to evaluate but no obvious malformation was seen. 
310 Regarding the development of foetus, hair distribution, Crown-Rump Length (CRL), and

311

312

313

314

315

316

317

318

319

320

321

322

323

324

325

326

327

328

329

330

331

332

333

334

335

336

337

338

339

340

341 weight, seem to indicate that GA-1 animals were in an earlier phase of development when compared with the aborted foetus from GB-1 (Table 2). Foetal ages based on CRL (Sivachelvan et al., 1996) were estimated at 70-100 days as suggested above.

Histopathological examination of brains from GA-1 and GB-1 foetuses showed similar lesions. There was a moderate to severe multifocal necrosis with mild gliosis and occasional and mild lymphohistiocitic perivascular infiltrates (Fig. 3G-H). The foetus from Rp 2 also had multifocal haemorrhages in both grey and white matter and the foetus from Rp 1 had mild multifocal deposits of basophilic granular extracellular material (calcium deposits). The mummified foetus was not examined histologically. The foetuses from GA-2/GB-2 animals did not present histopathological lesions. Histopathological lesions in the placentomes were seen in all GA-1/GB-1 pregnant chamois (Fig. 3E-F). The lesions ranged from oedema of the chorioallantoid membrane and multifocal cryptal dilation ( $R p 2$ ) to multifocal epithelial cryptal fibrinohaemorrhagic necrosis $(\mathrm{Rp} 1)$ to diffuse necrosis of the placentome ( $\mathrm{Rp} 10)$ with multifocal mineralization ( $\operatorname{Rp} 8)$.

Foetal tissues were also assessed for viral presence (Table 2). Foetuses from GA-1 presented the highest RNA load in the experiment. In one foetus from GB-1, viral RNA was widely distributed (placenta, brain and thymus) but with a difference of $10 \mathrm{Ct}$ (equivalent to more than a 1000-fold decrease in viral load) from foetuses of GA-1. Interestingly, a foetus from GA-2 presented viral RNA in the sera $(\mathrm{Ct}=35.24)$ and brain $(\mathrm{Ct}=36.19)$. The analysis of the 5'UTR region revealed that all foetuses except one were infected with the homologous virus inoculated in each group. The heterologous virus was detected in a foetus from GA-2 (Foetus Rp 6) and $243 \mathrm{pb}$ of the 5 'UTR region showed $100 \%$ identity with the same region of Freser-5 virus. This result strongly suggests that the foetus was already transplacentary infected before capture. All sera samples from foetuses were negative by VNT.

\section{Discussion}

After 17 years since the first outbreak of border disease (BD) in Pyrenean chamois and at least since 28 years of pestivirus presence in Pyrenean chamois populations, several studies have investigated the factors that rule the diversity of the epidemiological scenarios (Pioz et al., 2007; Martin et al., 2011; Fernández-Sirera et al., 2012; Marco et al., 2015). The present 
study unravel that pathogen virulence is most probably the main factor driving disease presentation and impact on chamois populations. BDV circulating strains in a certain geographic range is relevant to predicting the outbreak appearance and impact on the population and thus, to decide which management strategies to perform.

In previous BDV experimental infections in chamois with high-virulence strains, like BDV Cadí-6, the animals developed a long-lasting viraemia (Cabezón et al., 2011; Martin et al., 2013). The epidemiological consequences of these high-virulence strains have been exemplified in field studies by the reports of high mortality outbreaks in free-ranging populations. The highest mortality was recorded in 2005, when a BDV Cadí-like strain caused a drop of about $86 \%$ in the chamois population in the Cerdanya-Alt Urgell NHR (Marco et al., 2009). The present research demonstrates that, in horizontally-infected chamois, high RNA loads are excreted by nasal route and to a lower extent by rectal route, for at least 18 days. This, together with the findings of previous reports demonstrating these and vaginal and oral routes as a source of virus excretion (Cabezón et al., 2010a; 2011; Martin et al., 2013), strongly suggests that horizontal transmission has been the key factor in the reported severe epidemics in the Pyrenees. Moreover, the exceptionally long viraemia of high-virulence BDV strains in chamois may have been also of importance for the epidemiology of the disease. The acuteness and extreme severity of some of the epizootics may have been related to secondary infections, such as pneumonia, due to the immunosuppressive effects of coincident BDV infection, as suggested before (Marco et al., 2015).

The present research points-out some of the differences in clinical presentations observed between naturally and experimentally infected chamois. The main clinical alterations seen in chronic cases of naturally-infected chamois are neurological signs and alopecia (Marco et al., 2007). However, in this study no neurological signs were observed because the use of longacting tranquillizers may have masked the neurological clinical manifestations. A clinical presentation of BDV infection seen exclusively in experimental infections in chamois to date is the haemorrhagic diathesis. The suspected cause is a severe thrombocytopenia (Cabezón et al. 2011; Martin et al., 2013). This haemorrhagic diathesis has been reported in other pestiviruses such as BVDV-2 and CSFV, also associated with thrombocytopenia (Walz et al., 1999; 2001; Bautista et al., 2002). The fact that these lesions have not been found in naturally-infected chamois may be due to the acute course and death of affected chamois. In the wild, those animals may die in isolated places or be scavenged after death, making it very 
difficult to locate. In contrast, chamois with a more chronic and progressive disease develop encephalitis and the neurological signs that facilitate their sight and detection.

In contrast to the high-virulence BDV strains, the present study demonstrates the existence of low-virulent strains (i.e., the Freser-5 strain) in the Pyrenees, which is in accordance with the epidemiological scenario observed in some chamois populations from Pyrenees, such as FSNHR. In this area no mortality outbreaks have been observed although BDV has been present at least since 1996 (Marco et al., 2011). In our experiment, this presumptive low-virulence BDV strain, isolated from a healthy chamois in FS-NHR, caused a transient viraemia and was cleared after the development of a specific humoral immune response. The longest viraemia in these chamois was of 7 days, corresponding to the results seen previously in subclinical BDV infections in postnatal sheep and pig (Nettleton et al., 1998; Thabti et al., 2002; GarcíaPérez et al., 2009; Cabezón et al., 2010b,c). Also, a lower RNA load in lymphoid organs was observed when compared with infected chamois with high virulent strain. Although the lower virulent nature of this strain, the existence of few glial nodes in the brain of all infected chamois demonstrates its neurotropism. Regarding viral shedding, only in five nasal swab samples from three GB-1 chamois was viral genome detected and in much lower RNA loads than in GA-1. These differences were observed also in urine RT-qPCR analysis, where four out of five chamois of GA-1 presented viral shedding and none of the GB-1 chamois showed viral presence. Although RNA loads are based in Ct values as a semi-quantitative approach, differences between groups are in evidence.

The low virus excretion observed in chamois infected with low-virulence strains is in contrast with the previous experimental infections with high virulent strains (Cabezón et al., 2011; Martin et al., 2013), and may be of relevance for viral transmission in the field. The aforementioned epidemiological situation of Freser-Setcases NHR, together with the experimental infection, suggests that viral maintenance is through vertical transmission, most probably by PI animals. This fact is in contrast with the areas were high mortality outbreaks occurred, where horizontally-infected chamois exhibiting long-lasting viraemia and high virus excretion may play a key role in the epidemiology.

The existence of PI animals in Pyrenean chamois has not been demonstrated in the wild, but has been suggested in some studies and demonstrated in an experimental infection with a single chamois (Vautrain and Gibert, 2008; Cabezón et al., 2010a; Marco et al., 2011, 2015; Beauneé et al., 2015). Interestingly, the finding of a natural-infected foetus without 
antibodies, previous to the experimental infection, strongly suggests that it was a PI chamois. Although the onset of foetal immunocompetence in chamois is unknown and the time of infection cannot be determined, a parallelism with ewes may shed light. Fahey and Morris (1978) showed that foetal immunocompetence in sheep could be between 64-82 days of gestation. On the assumption that thissituation is similar in chamois, the fact that the foetus could be 70 days old and that neutralizing antibodies in the mother appear after 15 days of pestivirus infection, the foetus from the present work could have been naturally infected before the foetal immuncompetence.

In addition with the abortions of pregnant females inoculated with high-virulence strains, two pregnant females inoculated with the low-virulence strain aborted. Interestingly, foetal mortality in all pregnant females occurred during the first two weeks of infection. This can be expected since all high and low-virulence pestiviruses can cause abortions, stillbirth, mummifications and malformations, mainly during early stages of gestation (Loken, 1995; Nettleton et al., 1998). Macroscopic and histopathological lesions were seen in the placentomes and the aborted fetuses. Hemorrhagic and necrotizing lesions in the placentomes and the brain of the fetuses predominate over the inflammatory changes which consist only in the occasional perivascular lymphohistiocytic infiltrate. Multifocal to full band necrosis of the placentomes are consistent with those lesions described in BDV infection in sheep and goats (Maxie et al., 2007). While the infection in our study probably occurred between days 70 and 100 of pregnancy, the experimental infection with direct inoculation of a high infective viral dose may have increased the severity of the infection in the foetuses, as reported in ewes (Richardson et al., 1990). However, BDV strain Cadí-6 infecting GA-1 was detected in higher RNA loads in the foetal sera and tissues when compared to the lower load in low-virulence infected fetuses. Female pregnant chamois infected with high-virulence BDV often die before giving birth (Martin et al., 2013, Marco et al., 2015), but in lowvirulence BDV infections, despite the mortality of the foetus, pregnant females survive and overcome the infection, produce antibodies and eliminate the virus.

One chamois infected with the high-virulence strain seemed to clear the virus in sera, presented a low RNA load in tissues and shedding routes, and had mild lesions in the brain. The evolution of infection seen in this chamois was similar to that previously described in an 
experimentally-infected chamois that was able to clear the virus (Cabezón et al., 2011) and highlights the possibility that some chamois may overcome highly virulent BDV infection.

The antibody cross-protection between pestivirus species infections has been previously reported (Paton, 1995). The seropositive chamois naturally infected in the field (GA-2 and GB-2) did not present viral replication during the experimental infection. In addition, no abortions occurred and the foetuses were protected since they were vironegative at the end of the study. Interestingly, those animals were captured in Freser-Setcases NHR where the lowvirulence strains that are circulating may be hindering the entrance of more virulent strains. This is a situation of competition between virulence-differentiated strains in which the circulation of a low-virulence BDV could be beneficial. Nevertheless, it should be taken into account that the epidemiological scenario could rapidly change due to the high mutagenic rate of RNA viruses. The low-pathogenic strain circulating in FS-NHR may be a consequence of virulence attenuation. Studies of BVDV genetic diversity have underlined the fact that the low-virulence strains are better adapted to the host and are thus more prone to persist in natural conditions. However, periodic emergence of virulent pestiviruses occurs. A selection of viral mutants, that replicate more than the parent virus, would facilitate the emergence of more virulent strains causing extensive tissue damage and a burst of viral shedding (Bolin and Grooms, 2004). Despite the differences between BVDV and BDV, these cited works could guide us when trying to comprehend the first outbreaks in 2001 and their absence until that date and in other chamois populations.

To understand virulence, more studies are needed to analyse viral genetic diversity. As has been described for other pestiviruses (Risatti et al., 2005; Leifer et al., 2013; Wang et al., 2015), the identification of virulence-related viral genome regions could be essential for the prevention and management of infections. Continuing with this approach, the genetic relationships of different strains such as the recent BDV from the genogroup 8 that was reported to cause mortality in chamois (Caruso et al. 2017), may be of concern. Luzzago et al. (2016) demonstrated that the isolated BDV chamois strains are distributed in a geographical pattern. This pattern seems to be partially related to virulence in both strains assessed in the present study. The importance of genetic diversity in regions such as E2 may clarify the phylogenetic relationships between strains within a pathogenic perspective. 


\section{Conclusions}

473 The present study highlights the pathological and epidemiological implications of two close 474 phylogenetically-related BDV strains in the Pyrenean chamois. The existence of a low475 virulence strain has been confirmed experimentally and related to chamois population 476 infection dynamics in the area where it was isolated. Such strain, despite inducing foetal 477 death, may persist in the chamois population through PI animals and may induce cross478 protection against the entrance and disease associated to high-virulence strains. The present 479 study highlights that BDV strain virulence plays a key role in disease presentation and epidemiology in chamois populations.

\section{Acknowledgements}

483 This research was funded by Ministerio de Economía y Competitividad of the Spanish Government (reference project CGL2012-40057-C02-01). Andreu Colom-Cadena and Xavier Fernández-Aguilar were supported by the predoctoral FI-DGR program from the Government of Catalonia. The authors give special thanks to the rangers and staff of the National Hunting Reserves of Catalonia for their help on chamois captures.

\section{Conflict of interest statement}

490 None of the authors of this study has a financial or personal relationship with other people or organizations that could inappropriately influence or bias the content of the study.

\section{References}

Arnal, M., Fernández-de-Luco, D., Riba, L., Maley, M., Gilray, J., Willoughby, K., Vilcek, S. and Nettleton, P. F. (2004) A novel pestivirus associated with deaths in Pyrenean chamois (Rupicapra pyrenaica pyrenaica). J. Gen. Virol., 85(Pt 12), pp. 3653-7.

Bautista, M. J., Ruiz-Villamor, E., Salguero, F. J., Sanchez-Cordon, P. J., Carrasco, L. and Gomez-Villamandos, J. C. (2002) Early platelet aggregation as a cause of thrombocytopenia in classical swine fever. Vet. Pathol., 39(1), pp. 84-91.

Beaunée, G., Gilot-Fromont, E., Garel, M. and Ezanno, P. (2015) A novel epidemiological model to better understand and predict the observed seasonal spread of Pestivirus in Pyrenean chamois populations. Vet. Res., 46(1), p. 86. 
503

504

505

506

507

508

509

510

511

512

513

514

515

516

517

518

519

520

521

522

523

524

525

526

527

528

529

530

531

532

Bolin, S.R., Grooms, D.L. (2004) Origination and consequences of bovine viral diarrhea virus diversity. Vet. Clin. Food Anim., 20. 51-68.

Cabezón, O., Rosell, R., Velarde, R., Mentaberre, G., Casas-Diáz, E., Lavin, S. and Marco, I. (2010a) Border disease virus shedding and detection in naturally infected Pyrenean chamois (Rupicapra pyrenaica). J. Vet. Diagn. Invest., (22), pp. 744-747.

Cabezón, O., Velarde, R., Rosell, R., Lavín, S., Segalés, J. and Marco, I. (2010b) Experimental infection of lambs with Border disease virus isolated from a Pyrenean chamois, Vet. Rec., 167(16), pp. 619-21.

Cabezón, O., Rosell, R., Sibila, M., Lavin, S., Marco, I. and Segales, J. (2010c) Experimental infection of pigs with Border disease virus isolated from Pyrenean chamois (Rupicapra pyrenaica). J. Vet. Diagn. Invest., 22(3), pp. 360-365.

Cabezón, O., Velarde, R., Mentaberre, G., Fernández-Sirera, L., Casas-Díaz, E., LópezOlvera, J., Serrano, E., Rosell, R., Riquelme, C., Lavín, S., Segalés, J. and Marco, I. (2011) Experimental infection with chamois border disease virus causes long-lasting viraemia and disease in Pyrenean chamois (Rupicapra pyrenaica). J. Gen. Virol., 92(11), pp. 2494-2501.

Caruso, C., Peletto, S., Cerutti, F., Modesto, P., Robetto, S., Domenis, L., Masoero, L. and Acutis, P. L. (2017) Evidence of circulation of the novel border disease virus genotype 8 in chamois. Arch. Virol., 162(2), pp. 511-515.

Cavallero, S., Marco, I., Lavín, S., D’Amelio, S., López-Olvera, J. R., D’Amelio, S. and López-Olvera, J. R. (2012) Polymorphisms at MHC class II DRB1 exon 2 locus in Pyrenean chamois (Rupicapra pyrenaica pyrenaica). Infect. Genet. Evol., 12(5), pp. $1020-6$.

Fernández-Sirera, L., Cabezón, O., Allepuz, A., Rosell, R., Riquelme, C., Serrano, E., Lavín, S. and Marco, I. (2012) Two Different Epidemiological Scenarios of Border Disease in the Populations of Pyrenean chamois (Rupicapra p. pyrenaica) after the First Disease Outbreaks. PLoS One, 7(12), pp. 1-10.

García-Pérez, A. L., Minguijón, E., Estévez, L., Barandika, J. F., Aduriz, G., Juste, R. A. and Hurtado, A. (2009) Clinical and laboratorial findings in pregnant ewes and their progeny infected with Border disease virus (BDV-4 genotype). Res. Vet. Sci., 86(2), 
Gilot-Fromont, E., Foulche, K., Game, Y., Ezanno, P., Marco, I., Gibert, Ph. (2015) Le pestivirus et les isards une interaction durable. Faune sauvage, vol. 307. pp.17-22

Hurtado, A., Sanchez, I., Bastida, F., Minguijón, E., Juste, R. A. and García-Pérez, A. L. (2009) Detection and quantification of pestivirus in experimentally infected pregnant ewes and their progeny. Virol. J., 6, p. 189.

Kaiser, V., Nebel, L., Schüpbach-Regula, G., Zanoni, R. G. and Schweizer, M. (2017) Influence of border disease virus (BDV) on serological surveillance within the bovine virus diarrhea (BVD) eradication program in Switzerland. BMC Vet. Res. BMC Veterinary Research, 13(1), p. 21.

Leifer, I., Ruggli, N. and Blome, S. (2013) Approaches to define the viral genetic basis of classical swine fever virus virulence. Virology, 438(2), pp. 51-55.

Loken, T. (1995) Border disease in sheep. Vet. Clin. North Am. Food Anim. Pr., 11(3), pp. $579-595$.

López-Olvera, J. R., Marco, I., Montané, J., Casas-Díaz, E., Mentaberre, G. and Lavín, S. (2009) Comparative evaluation of effort, capture and handling effects of drive nets to capture roe deer (Capreolus capreolus), Southern chamois (Rupicapra pyrenaica) and Spanish ibex (Capra pyrenaica). Eur. J. Wildl. Res., 55(3), pp. 193-202.

Luzzago, C., Ebranati, E., Cabezó, O., Fernández-Sirera, L., Lavín, S., Rosell, R., Veo, C., Rossi, L., Cavallero, S., Lanfranchi, P., Marco, I. and Zehender, G. (2016) Spatial and temporal phylogeny of border disease virus in Pyrenean Chamois (Rupicapra $p$. pyrenaica). PLoS One, pp. 1-17.

Marco, I., Lopez-Olvera, J. R., Rosell, R., Vidal, E., Hurtado, A., Juste, R., Pumarola, M. and Lavin, S. (2007) Severe outbreak of disease in the southern chamois (Rupicapra pyrenaica) associated with border disease virus infection. Vet. Microbiol., 120(1-2), pp. $33-41$.

Marco, I., Rosell, R., Cabezón, O., Mentaberre, G., Casas, E., Velarde, R. and Lavín, S. (2009) Border disease virus among chamois, Spain. Emerg. Infect. Dis., 15(3), pp. $448-51$. 
562

563

564

565

566

567

568

569

570

571

572

573

574

575

576

577

578

579

580

581

582

583

584

585

586

587

588

589

Marco, I., Cabezón, O., Rosell, R., Fernández-Sirera, L., Allepuz, A. and Lavín, S. (2011) Retrospective study of pestivirus infection in Pyrenean chamois (Rupicapra pyrenaica) and other ungulates in the Pyrenees (NE Spain). Vet. Microbiol., 149(12), pp. 17-22.

Marco, I., Cabezón, O., Velarde, R., Fernández-Sirera, L., Colom-Cadena, A., Serrano, E., Rosell, R., Casas-Díaz, E. and Lavín, S. (2015) The two sides of border disease in Pyrenean chamois (Rupicapra pyrenaica): silent persistence and population collapse. Anim. Heal. Res. Rev., 16(1), pp. 70-77.

Martin, C., Duquesne, V., Guibert, J.-M., Pulido, C., Gilot-Fromont, E., Gibert, P., Velarde, R., Thiéry, R., Marco, I. and Dubois, E. (2013) Experimental Infection of Pregnant Pyrenean Chamois (Rupicapra Pyrenaica) With Border Disease Virus Subtype 4. J. Wildl. Dis., 49(1), pp. 55-68.

Maxie, M. G., Jubb, K. V. F., Kennedy, P. C., Palmer, N. (2007). Jubb, Kennedy, and Palmer's pathology of domestic animals. Edinburgh: Elsevier Saunders.

Nettleton, P. F., Gilray, J. A., Russo, P. and Dlissi, E. (1998) Border disease of sheep and goats. Vet Res, 29, pp. 327-340.

Nolan, T., Hands, R. E. and Bustin, S. A. (2006) Quantification of mRNA using real-time RT-PCR. Nat. Protoc., 1(3), pp. 1559-1582.

Fahey, K. and Morris B. (1978) Humoral immune responses in foetal sheep. Immunology, 35(4), pp. 651-661.

OIE (2014) Terrestrial manual. Chapter 2.7.1. Border Disease.

Paton, D. J. (1995) Pestivirus diversity. J. Comp. Pathol., pp. 215-236.

Pioz, M., Loison, A., Gibert, P., Dubray, D., Menaut, P., Le Tallec, B., Artois, M. and GilotFromont, E. (2007) Transmission of a pestivirus infection in a population of Pyrenean chamois. Vet. Microbiol., 119(1), pp. 19-30.

R Development Core Team (2016) R: A Language and Environment for Statistical Computing. R Found. Stat. Comput. Vienna Austria. 
Richardson, C., Jones, P. C., Barnard, V., Hebert, C. N., Terlecki, S. and Wijeratne, W. V (1990) Estimation of the developmental age of the bovine fetus and newborn calf. Vet. Rec., 126(12), pp. 279-284.

Risatti, G. R., Borca, M. V, Kutish, G. F., Lu, Z., Holinka, L. G., French, R. A., Tulman, E. R. and Rock, D. L. (2005) The E2 Glycoprotein of Classical Swine Fever Virus Is a Virulence Determinant in Swine, J. Virol., 79(6), pp. 3787-3796.

Sawyer, M. M., Schore, C. E. and Osburn, B. I. (1991) Border disease of sheep - Aspects for diagnostic and epidemiologic consideration. Arch. Virol. Suppl., pp. 97-100.

Scherer, C. F. C., Flores, E. F., Weiblen, R., Caron, L., Irigoyen, L. F., Neves, J. P. and Maciel, M. N. (2001) Experimental infection of pregnant ewes with bovine viral diarrhea virus type-2 (BVDV-2): Effects on the pregnancy and fetus. Vet. Microbiol., 79(4), pp. 285-299.

Tautz, N., Tews, B. A. and Meyers, G. (2015) The Molecular Biology of Pestiviruses. Adv. Virus Res., pp. 47-160

Thabti, F., Fronzaroli, L., Dlissi, E., Guibert, J. M., Hammami, S., Pepin, M. and Russo, P. (2002) Experimental model of Border Disease virus infection in lambs: Comparative pathogenicity of pestiviruses isolated in France and Tunisia. Vet. Res., 33(1), pp. 3545.

Vautrain, G. and Gibert, P. (2008) Le Pestivirus de l'isard contamine-t-il les ovins ? Résultats d'expérimentations. Faune Sauvag., 282, pp. 46-50.

Vilček, S., Herring, A. J., Herring, J. A., Nettleton, P. F., Lowings, J. P. and Paton, D. J. (1994) Pestiviruses isolated from pigs, cattle and sheep can be allocated into at least three genogroups using polymerase chain reaction and restriction endonuclease analysis. Arch. Virol., 136, pp. 309-323.

Walz, P. H., Steficek, B. A., Baker, J. C., Kaiser, L. and Bell, T. G. (1999) Effect of experimentally induced type II bovine viral diarrhea virus infection on platelet function in calves. Am. J. Vet. Res., 60(11), pp. 1396-1401.

Walz, P. H., Bell, T. G., Grooms, D. L., Kaiser, L., Maes, R. K. and Baker, J. C. (2001) Platelet aggregation responses and virus isolation from platelets in calves 

experimentally infected with type I or type II bovine viral diarrhea virus. Can. J. Vet. Res., 65(4), pp. 241-7.

Wang, F. I., Deng, M. C., Huang, Y. L. and Chang, C. Y. (2015) Structures and functions of pestivirus glycoproteins: Not simply surface matters. Viruses, 7(7), pp. 3506-3529.

\section{$(2)$}

Figure 1. BDV-4 RNA load obtained by Real-time RT-PCR and neutralizing antibody titres by Virus Neutralization Test (VNT) in sera samples. PCR results are presented in threshold cycle (Ct). A) Mean $\mathrm{Ct}$ values of positive samples and median VNT titres; B) individual $\mathrm{Ct}$ values in each chamois and time of sampling. The limit of detection was established on $\mathrm{Ct}$ value $\geq 40$. GA: Group infected with Cadí-6 BDV strain; GB: Group infected with Freser-5 BDV strain. Subgroups according to antibody presence at the beginning of the experiment: without antibodies (numbered as 1) or with antibodies (numbered as 2).

Figure 2. BDV-4 RNA load obtained by Real-time RT-PCR in nasal and rectal swabs. Results are presented in threshold cycle $(\mathrm{Ct})$. A) Mean $\mathrm{Ct}$ values of positive samples in nasal fluids; B) individual Ct values in each chamois and time of sampling in nasal fluids; C) Mean $\mathrm{Ct}$ values of positive samples in rectal swabs; D) individual $\mathrm{Ct}$ values in each chamois and time of sampling in rectal swabs. The limit of detection was established at $\mathrm{Ct}$ value $\geq 40$. GA: 1-7; Group infected with Cadí-6 BDV strain; GB: 8-15; Group infected with Freser-5 BDV strain. Subgroups according to antibody presence at the beginning of the experiment: without antibodies (numbered as 1) or with antibodies (numbered as 2).

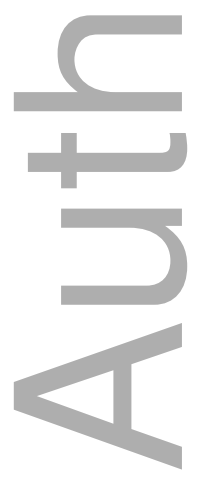


640 Figure 3. Failure of pregnancy in female adult chamois experimentally infected with border 641 disease virus-4. (A, B) Opened uterus with haemorrhagic contents, placental oedema and 642 dead foetus, Rp 2. (C, D) Opened uterus with necrotic placentomes, foetal death and 643 malformation - brachygnathia superior and inferior, Rp 10. (E, F) Histopathologic findings 644 in placentomes, oedema and haemorhages of chorioallantoid membrane and multifocal 645 haemorrhagic necrosis at the base of caruncles with epithelial attenuation and cryptal dilation, 646 Rp 2. (G) Brain foetus, with focal haemorrhages and mild lymphohistiocytic perivascular 647 infiltrates, Rp 2. (H) Brain foetus, multifocal necrotizing encephalitis and gliosis, Rp 10.

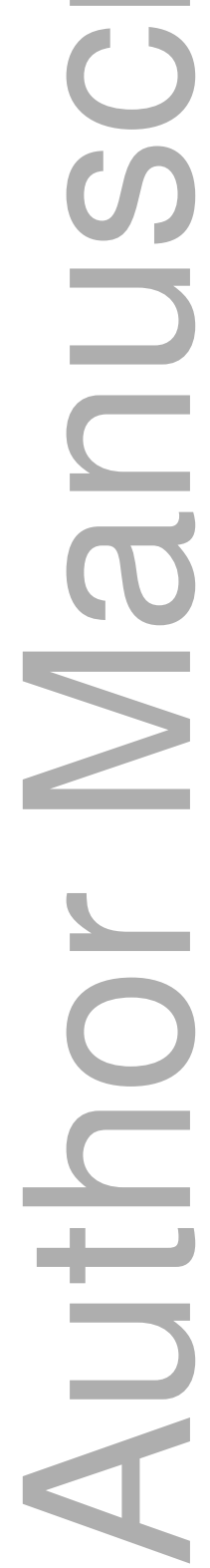


Table 1 Challenge groups, GA: Group infected with Cadí-6 BDV strain; GB: Group infected with Freser-5 BDV strain and Real-time reverse

650 transcriptase-PCR results in tissue samples at time of necropsy. Real-time RT-PCR results are presented in threshold cycle (Ct). The limit of

\begin{tabular}{|c|c|c|c|c|c|c|c|c|c|c|c|c|c|}
\hline \multirow{2}{*}{ Group ID } & \multirow[b]{2}{*}{ Sex } & \multirow[b]{2}{*}{ Pregnancy } & \multicolumn{11}{|c|}{ Real-time RT-PCR $(\mathrm{Ct})$} \\
\hline & & & Subm. LN & Retrofa. LN & Tonsil & Peyer patch & Spleen & Liver & Lungs & Kidney & Bone marrow & Brain & Urine \\
\hline \multirow{5}{*}{ 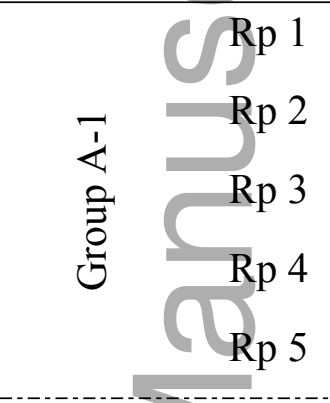 } & $\mathrm{F}$ & Yes & 19.64 & 19.60 & 19.00 & 21.80 & 27.27 & 24.88 & 20.57 & 27.31 & 20.56 & 21.25 & 22.66 \\
\hline & $\mathrm{F}$ & Yes & 22.08 & 22.83 & ns & $\mathrm{u}$ & $\mathrm{u}$ & $\mathrm{u}$ & 20.90 & $\mathrm{u}$ & 22.88 & 21.59 & 20.48 \\
\hline & M & & 29.32 & $\mathrm{u}$ & 30.35 & $\mathrm{u}$ & 29.90 & $\mathrm{u}$ & $\mathrm{u}$ & $\mathrm{u}$ & $\mathrm{u}$ & $\mathrm{u}$ & $\mathrm{u}$ \\
\hline & $\mathrm{F}$ & No & 22.89 & 26.04 & ns & $\mathrm{u}$ & $\mathrm{u}$ & 31.95 & 25.61 & $\mathrm{u}$ & 28.30 & $\mathrm{u}$ & 27.16 \\
\hline & $\mathrm{F}$ & No & 19.85 & 21.00 & 22.21 & 24.64 & $\mathrm{u}$ & 32.24 & 21.16 & $\mathrm{u}$ & 23.18 & 21.94 & 28.08 \\
\hline \multirow{2}{*}{$\begin{array}{ll}\text { Group A-2 } & \operatorname{Rp} 6 \\
& \operatorname{Rp} 7\end{array}$} & $\mathrm{~F}$ & Yes & $\mathrm{u}$ & $\mathrm{u}$ & ns & $\mathrm{u}$ & $\mathrm{u}$ & $\mathrm{u}$ & $\mathrm{u}$ & $\mathrm{u}$ & $\mathrm{u}$ & $\mathrm{u}$ & $\mathrm{u}$ \\
\hline & $\mathrm{F}$ & Yes & $\mathrm{u}$ & $\mathrm{u}$ & ns & $\mathrm{u}$ & $\mathrm{u}$ & $\mathrm{u}$ & $\mathrm{u}$ & $\mathrm{u}$ & $\mathrm{u}$ & $\mathrm{u}$ & $\mathrm{u}$ \\
\hline \multirow{6}{*}{$\begin{array}{l}\bar{n} \\
\stackrel{1}{0} \\
\stackrel{0}{0} \\
\dot{0}\end{array}$} & $\mathrm{~F}$ & Yes & $\mathrm{u}$ & $\mathrm{u}$ & 31.01 & $\mathrm{u}$ & $\mathrm{u}$ & $\mathrm{u}$ & $\mathrm{u}$ & $\mathrm{u}$ & $\mathrm{u}$ & $\mathrm{u}$ & $\mathrm{u}$ \\
\hline & M & & 27.42 & 25.60 & 27.18 & 34.51 & $\mathrm{u}$ & 38.12 & 35.58 & $\mathrm{u}$ & $\mathrm{u}$ & $\mathrm{u}$ & $\mathrm{u}$ \\
\hline & $\mathrm{F}$ & Yes & $\mathrm{u}$ & $\mathrm{u}$ & 34.42 & $\mathrm{u}$ & $\mathrm{u}$ & $\mathrm{u}$ & $\mathrm{u}$ & $\mathrm{u}$ & $\mathrm{u}$ & $\mathrm{u}$ & $\mathrm{u}$ \\
\hline & M & & $\mathrm{u}$ & 32.18 & $\mathrm{u}$ & $\mathrm{u}$ & $\mathrm{u}$ & $\mathrm{u}$ & 38.20 & $\mathrm{u}$ & $\mathrm{u}$ & $\mathrm{u}$ & $\mathrm{u}$ \\
\hline & $\mathrm{F}$ & No & 33.67 & 33.22 & $\mathrm{u}$ & $\mathrm{u}$ & $\mathrm{u}$ & $\mathrm{u}$ & $\mathrm{u}$ & $\mathrm{u}$ & $\mathrm{u}$ & $\mathrm{u}$ & $\mathrm{u}$ \\
\hline & M & & 31.57 & 31.59 & $\mathrm{u}$ & $\mathrm{u}$ & $\mathrm{u}$ & $\mathrm{u}$ & $\mathrm{u}$ & $\mathrm{u}$ & $\mathrm{u}$ & $\mathrm{u}$ & $\mathrm{u}$ \\
\hline \multirow{2}{*}{ Group B-2 } & $\mathrm{F}$ & Yes & $\mathrm{u}$ & $\mathrm{u}$ & ns & $\mathrm{u}$ & $\mathrm{u}$ & $\mathrm{u}$ & $\mathrm{u}$ & $\mathrm{u}$ & $\mathrm{u}$ & $\mathrm{u}$ & $\mathrm{u}$ \\
\hline & $\mathrm{F}$ & Yes & $\mathrm{u}$ & $\mathrm{u}$ & ns & $\mathrm{u}$ & $\mathrm{u}$ & $\mathrm{u}$ & $\mathrm{u}$ & $\mathrm{u}$ & $\mathrm{u}$ & $\mathrm{u}$ & $\mathrm{u}$ \\
\hline
\end{tabular}

This article is protected by copyright. All rights reserved 
651 detection was established at $\mathrm{Ct}$ value $\geq 40$. $\mathrm{u}=$ undetected, no viral $\mathrm{RNA}$ was found; ns=not sampled; Subm.=submandibular;

652 Retrofa. $=$ retropharyngeal.

653 Table 2 Foetus information, GA: Group infected with Cadí-6 BDV strain; GB: Group infected with Freser-5 BDV strain. CRL (Crown-rump

654 length). Neutralizing antibody titres obtained by Virus Neutralization Test (VNT) and real-time RT-PCR results in tissue samples at time of 655 necropsy, Real-time RT-PCR Results are presented in threshold cycle $(\mathrm{Ct})$. The limit of detection was established at $\mathrm{Ct}$ value $\geq 40$.

$656 \mathrm{u}=$ undetected, no viral RNA was found; $n s=$ not sampled.

Real-time RT-PCR (Ct)

Group ID Sex Viability CRL (cm) Weight Hair distribution Hoof formation VNT titres Sera Placentome Brain Thymus Spleen

\begin{tabular}{|c|c|c|c|c|c|c|c|c|c|c|c|c|c|}
\hline \multirow{2}{*}{ Group A-1 } & Foetus Rp 1 & $\mathrm{~F}$ & Dead & 23 & 515 & Lips, chin & Initial & 0 & 14.92 & 16.74 & 24.57 & 19.45 & 25.84 \\
\hline & Foetus Rp 2 & $\mathrm{~F}$ & Dead & 24 & 609 & Lips, chin & Initial & 0 & 14.49 & 17.75 & 23.01 & 29.13 & $\mathrm{u}$ \\
\hline \multirow{2}{*}{ Group A-2 } & Foetus $\operatorname{Rp} 6$ & M & Yes & 30 & 882 & Whole body & Complete & 0 & 35.24 & $\mathrm{u}$ & 36.19 & $\mathrm{u}$ & $\mathrm{u}$ \\
\hline & Foetus $\mathrm{Rp} 7$ & $\mathrm{~F}$ & Yes & 27 & 597 & Head & Complete & 0 & ns & $\mathrm{u}$ & $\mathrm{u}$ & $\mathrm{u}$ & $\mathrm{u}$ \\
\hline \multirow{2}{*}{ Group B-1 } & Foetus Rp 8 & ND & Mummified & ND & ND & ND & ND & 0 & ns & 25.40 & $\mathrm{u}$ & ns & $\mathrm{u}$ \\
\hline & Foetus Rp 10 & $\mathrm{M}$ & Aborted & 30 & 877 & Whole body & Complete & 0 & $\mathrm{u}$ & 27.49 & 34.53 & 31.92 & $\mathrm{u}$ \\
\hline Group B-2 & Foetus Rp 14 & $\mathrm{~F}$ & Yes & 26.5 & 587 & Whole body & Complete & 0 & $\mathrm{u}$ & $\mathrm{u}$ & $\mathrm{u}$ & $\mathrm{u}$ & $\mathrm{u}$ \\
\hline
\end{tabular}


A)
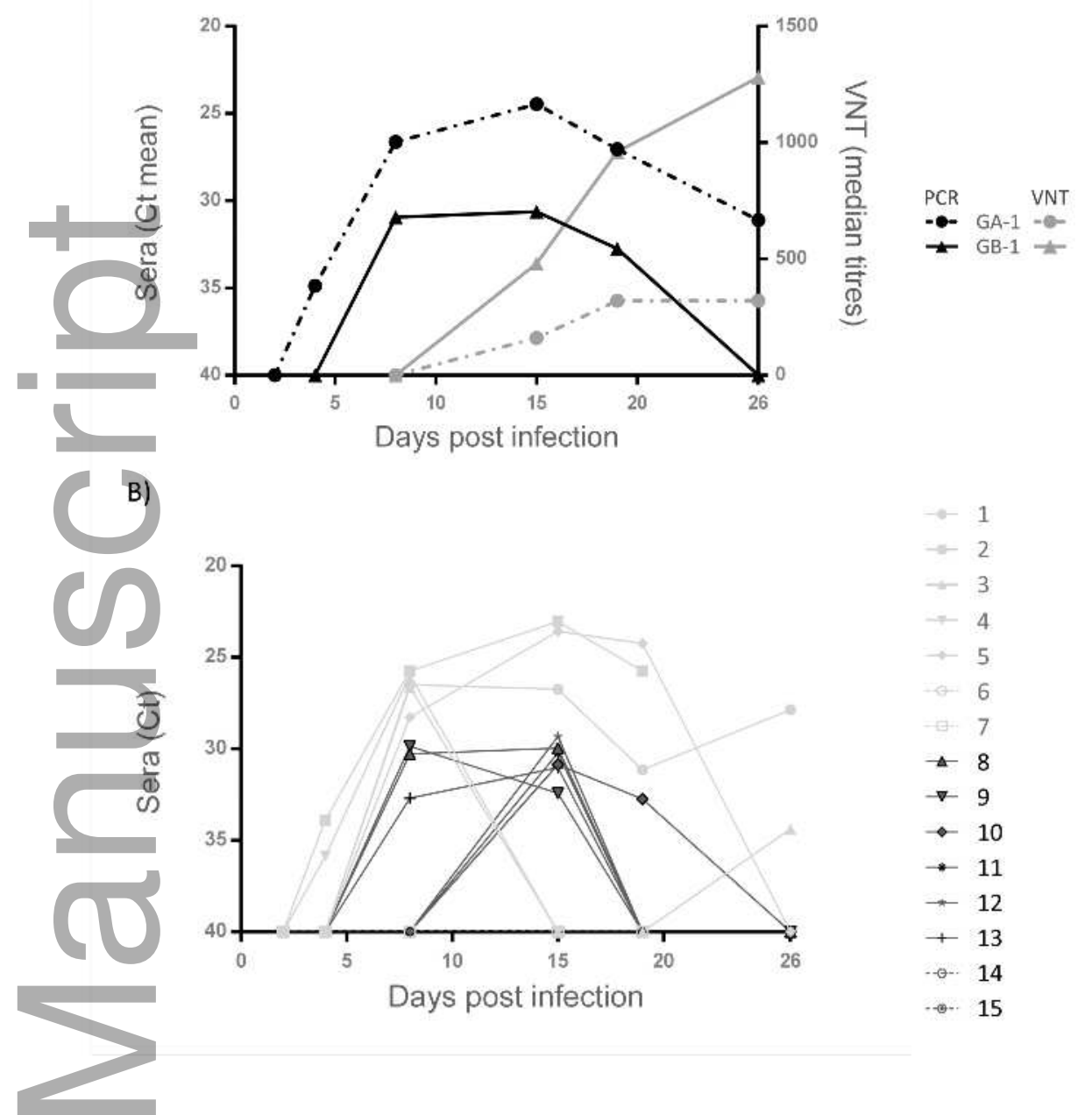

1
$-\quad 2$

$-3$

$\div 4$

$\rightarrow 5$

-6 6

-7
$-\quad 7$

- 8

$\rightarrow 9$

$\rightarrow 10$

$\rightarrow 11$

$\rightarrow 12$

$+13$

- $\rightarrow 14$

- - 15

tbed_13195_f1.tif

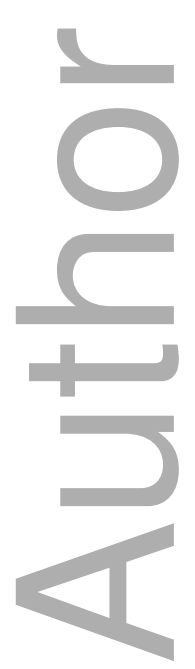


A)

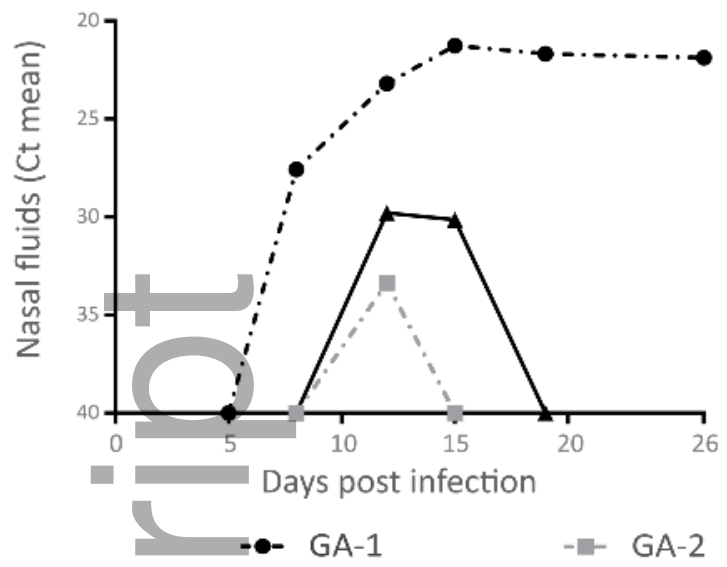

B)

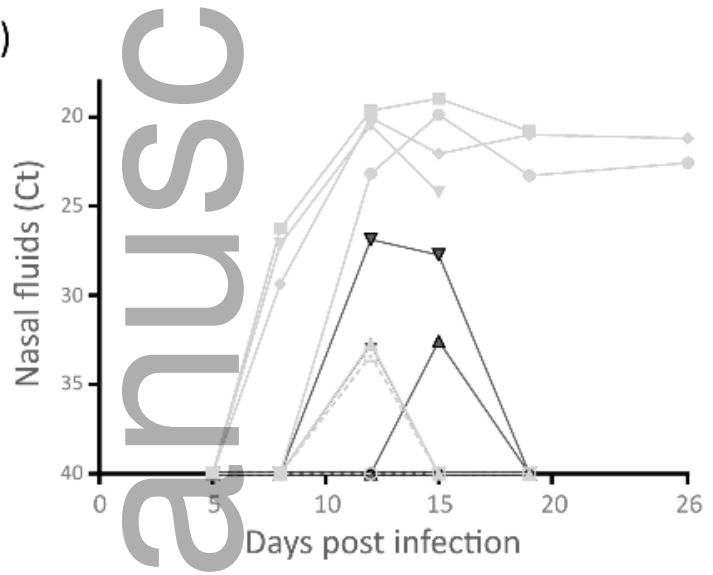

C)

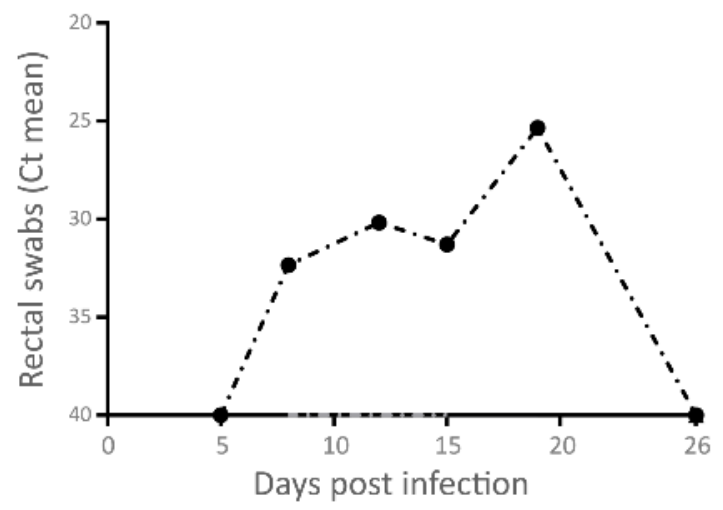

D)

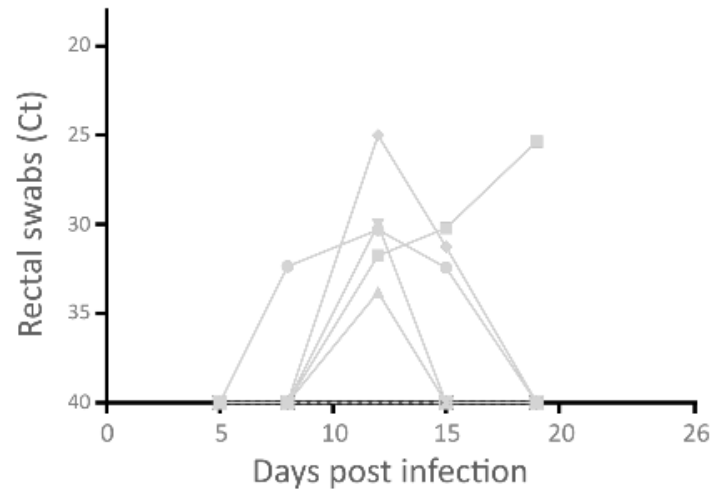

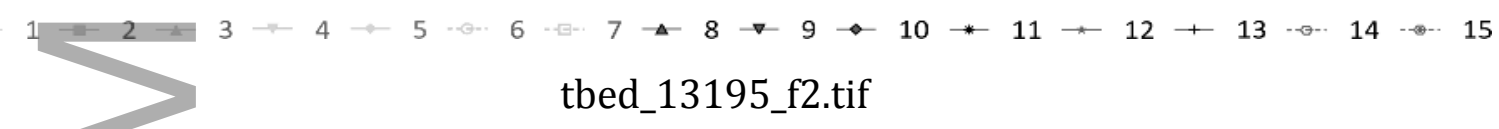

tbed_13195_f2.tif 


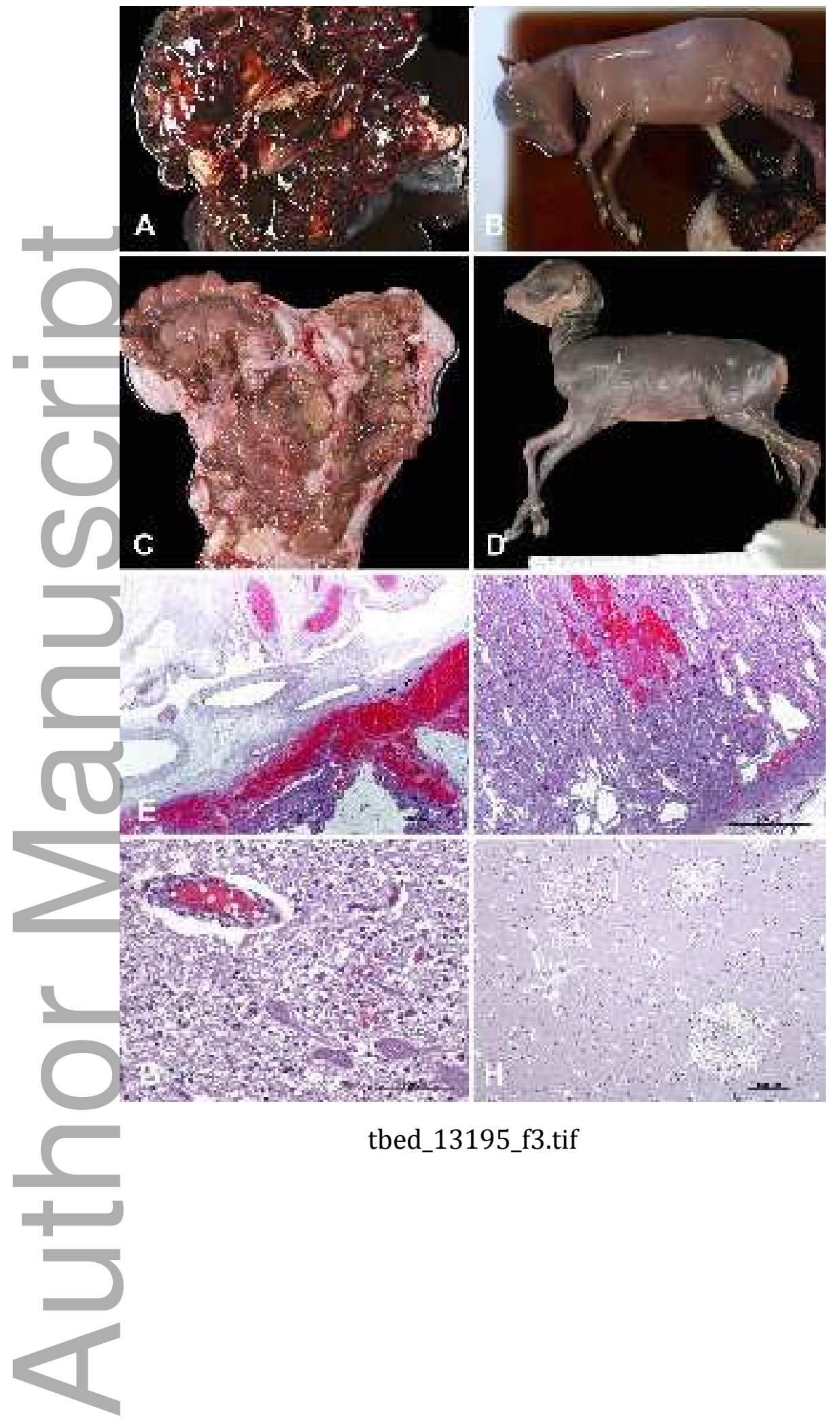

This article is protected by copyright. All rights reserved 